project addresses the design and development of on-line education resources (OERs) about sex, intimacy and relationships for and with young people, age $16+$, with lifelimiting and or life threatening conditions (LLTCs). This builds upon previous research but where young adults with LLTCs were consulted but not formally contracted as coresearchers.

Methods This project uses an inclusive, action research model designed to support the transition of young people who are life-limited or life-shortened, by developing their confidence in talking about sex, intimacy and relationships with family, friends, care practitioners and other carers.

Findings/Results The presentation will address the merits and some of the ethical challenges of collaborating with co-researchers who have LLTCs; particularly when the university researchers also include both academics and policy researchers with a clinical background. We shall discuss how, together, we have developed, on-line education resources about relationships, intimacy and sex via The Open University's, Open Learn Portal. Addressing the duty of care to individuals with a LLTC who may become ill during the project should also be balanced with the responsibilities of researchers to complete and deliver a funded project in a timely fashion. These aspects will also be addressed.

Conclusion Much innovative, inclusive research is methodologically orientated, and may focus more about the process rather than the deliverables and the outcomes (Blackburn, 2018). This project focuses on the outcomes, contribution to knowledge and the impact about a very specific, niche area of sexuality, whilst seeking to include the important methodological innovations of co-research.

\section{P-149 TALKING ABOUT SEX AND RELATIONSHIPS: YOUNG PEOPLE WITH LIFE-LIMITING AND LIFE-THREATENING CONDITIONS SPEAK OUT}

${ }^{1}$ Maddie Blackburn, ${ }^{1}$ Sarah Earle, ${ }^{1}$ Lucy Watts, ${ }^{1}$ Alison Cooke, ${ }^{2}$ Claire De Than. ${ }^{1}$ The Open University, Milton Keynes, UK; ${ }^{2}$ City of London University, London, UK

\subsection{6/bmjspcare-2019-HUKNC.171}

Background Due to advances in medical treatment and care, increasing numbers of young people with life-limiting or lifethreatening conditions (LLTCs) are surviving into adulthood (Beresford \& Stuttard, 2014). Growing evidence suggests that they are not always equipped to do so. There is an absence of tailored support in the important area of sex, intimacy and relationships (Blackburn, 2018) To address this gap, our research has informed the publications of guidance and standards and the development of on-line education resources (OERs) about relationships, intimacy and sex, via The Open University's Open Learn Portal. Sex, intimacy and relationships are central to all four phases of the transition journey. Many family members, carers and professional staff often feel unequipped to develop services that meet these needs (Blackburn, Chambers, Earle, De Than et al, 2016).

Aims The project aims to support young people within this often neglected and important area of transition into adult life. The development of OERs will help to overcome an absence of services and support in this field. Our research shows that people want to talk about sex, with family, carers or professional support staff.
Methods Adopting an inclusive approach and working in partnership with individuals with LLTCs, service providers and other organisations, the development of the OERS about sex are being co-designed and presented by disabled people, particularly those, with LLTCs.

Results The (OERs) are nearing completion and will be available for presentation at the forthcoming conference. The OERs include discussions by people with LLTCs who are either in relationships or would like to be intimate or to have sex. Topics include access to information about sex throughout life, taboos about sex, practicalities of intimacy for disabled people, sex aids and aspects of the law and governance.

Conclusion The OERs will help young people and their supporters address this invisible topic through knowledge, resources and lead to a better understanding of their views and experiences.

\section{P-150 HOSPICE IN-PATIENT UNIT: WHAT'S IMPORTANT TO ME - HELPING PATIENTS ACHIEVE THEIR GOALS}

Elizabeth Millett, Tracy Parkinson, Maureen Howe. St Catherine's Hospice, Preston, UK

\subsection{6/bmjspcare-2019-HUKNC.172}

Background An individualised approach is the focus of palliative care. It was recognised by staff that achieving genuine holistic care was becoming more difficult, due to the increasing complexity of patient needs. The team decided to create a process for identifying what was important for patients to help achieve their goals.

Aim Offer patients a recognised way to share what is important to them on a daily basis.

Method Background research showed seven local hospices did not have a process like this in place, but anecdotally thought it would provide benefit to patients. An audit of patient and family views provided positive feedback. Postcards have been printed for patients to write what is important to them, on a particular day. These are shared with staff directly or to maintain privacy, special folders have been provided. The process is explained on admission and posters placed in each room to raise awareness for patients and family. Using the postcards is completely voluntary. Staff and rehabilitation volunteers were provided with training regarding collecting postcards and responding to the patients' needs.

Results One week in:

- $12 / 13$ patients had access to resources;

- 13/13 patients had posters in their rooms;

- Five patients had used their cards;

- Three patients were too unwell;

- Remaining patients either didn't want to engage or planned to do so in the future.

Patients' words from postcards 'I would like to see the hairdresser'

'I would like to wake up alive tomorrow'

Future plans Plans are in place for a template to be created within the patient's electronic record to document patient needs identified and outcomes. The process will be audited quarterly to identify trends and evaluate patient benefit and evidence psychological care.

Conclusion Patients reported feeling much better for achieving their goals and the postcards offered reassurance their needs wouldn't be forgotten. 